\title{
Optimised design of silicon heterojunction solar cells for field operating conditions
}

\author{
Jean Cattin, Olivier Dupré, Brahim Aïssa, Jan Haschke, Christophe Ballif, Mathieu Boccard
}

\begin{abstract}
Solar modules are currently characterised at standard test conditions (STC), defined at $1000 \mathrm{~W} / \mathrm{m}^{2}$ and $25{ }^{\circ} \mathrm{C}$. However, solar modules in actual outdoor operating conditions typically operate at lower illumination and higher temperature than STC, which significantly affects their performance ratio (average harvesting efficiency over efficiency in STC). Silicon heterojunction (SHJ) technology displays both good temperature coefficient and good low-illumination performances, leading to outstanding performance ratios. We investigate here $\mathrm{SHJ}$ solar cells that use $\mathbf{a}-\mathrm{SiC}_{\mathbf{x}}(\mathrm{n})$ layer as front doped layer with different carbon contents under different climates conditions. Adding carbon increases transparency but also resistive losses at room temperature (compared to carbon-free layers), leading to a significant decrease in efficiency at STC. We demonstrate that despite this difference at STC, the difference in energy harvesting efficiency is much smaller in all investigated climates. Furthermore, we show that a relative gain of $0.4 \%$ to $0.8 \%$ in harvesting efficiency is possible by adding a certain content of carbon in the front (n) layer, compared to carbon-free cells optimised for STC.
\end{abstract}

\section{INTRODUCTION}

Solar cells and modules are generally characterised at - and thus optimised for-standard test conditions (STC), which correspond to a temperature of $25^{\circ} \mathrm{C}$ and an illumination of $1000 \mathrm{~W} / \mathrm{m}^{2}$ with the AM1.5G spectrum. The power output under these test conditions leads to the Watt-peak rating that nowadays dictates the selling price of modules. However, these conditions very rarely correspond to the actual operating conditions of a module in the field, which typically operates at higher temperatures and/or lower illumination than STC [1]-[5]. The new IEC 61853-4 standard on module energy rating includes this perspective by requiring multiple temperature-illumination measurements [6]. This is illustrated in Fig. 1A-E which show the yearly produced energy for a typical installation as a function of the operating conditions. The conditions follow from the different climates at the different locations shown in Fig. 1F. These maps are further explained in the discussion, but two important observations should be highlighted:

J. Cattin, O. Dupré, J. Haschke, M. Boccard, C. Ballif are with the Photovoltaics and Thin-Film Electronics Laboratory, Institute of

Microengineering, Ecole Polytechnique Fédérale de Lausanne, 2000

Neuchâtel, Switzerland. (e-mails: jean.cattin@epfl.ch,

olivier.dupre@epfl.ch, jan.haschke@epfl.ch,

Mathieu.boccard@epfl.ch, Christophe.ballif@epfl.ch)

B. Aïssa is with Qatar Environment and Energy Research Institute, Hamad bin Khalifa University, Qatar Foundation, P.O. Box 5825, Doha, Qatar (e-mail: baissa@hbku.edu.qa)
1) STC is not a representative operating condition set in any climate, as, over a year, almost no energy is generated at this particular condition.

2) In different climates, the energy is harvested under different conditions, yet most of the relevant conditions correspond to either higher temperature than STC or lower irradiance (or both).

Such changes of operating conditions have implications on the solar cell performances. To take field conditions into account, we define the harvesting efficiency ( $\eta_{\text {harvesting }}$ ) as the yearly produced energy divided by the cumulated in-plane irradiance:

$$
\eta_{\text {harvesting }}[\%]=\frac{\text { Energy produced }\left[\mathrm{W} \mathrm{h} / \mathrm{m}^{2}\right]}{\text { In-plane irradiance }\left[\mathrm{W} \mathrm{h} / \mathrm{m}^{2}\right]}
$$

The performance ratio, commonly used to characterise a module in a specific climate, is defined as the harvesting efficiency in a given climate divided by the STC efficiency [7]. All silicon solar cells are subject to a fundamental efficiency decrease upon increasing temperature, at a rate defined as the temperature coefficient (TC) [2], [8]. As shown in [9], series resistance can also have an impact on the TC of solar modules. This efficiency decrease is mainly driven by the increasing intrinsic carrier concentration, leading to lower operating voltage that is not balanced by the slightly increasing current. The general approach to maximise the efficiency at high temperature is to maximise the efficiency at STC and minimize TC. One way to achieve the latter is to increase the solar cell's $\mathrm{V}_{\mathrm{oc}}$, as described by the relation proposed by Green et al. [10]:

$$
T C_{V o c}=-\frac{\frac{E_{g 0}^{S i}}{q}-V_{o c}^{S T C}+\gamma k T}{T}
$$

The requirement for a high $\mathrm{V}_{\mathrm{oc}}$ makes the SHJ technology one of the most interesting candidates for hot climate operation [11], [12], thanks to the excellent surface passivation provided by the thin intrinsic hydrogenated amorphous silicon layers (a-Si(i)) yielding $\mathrm{V}_{\text {oc }}$ values above $730 \mathrm{mV}$ and resulting in $\mathrm{TC}_{\eta}$ in the range of -0.23 to $-0.29 \%$ $\mathrm{K}^{-1}$ [13], [14], the differences being linked in parts to the phenomena described further below. SHJ solar cell technology was already demonstrated to be more efficient in hot climates than equivalent-STC-efficiency modules with other types of silicon-based cells [9].

Another specificity of SHJ cells is the presence of non-Ohmic resistances that hinder both the collection of electrons and holes towards their respective electrodes. These resistances are typically attributed to energy barriers in the form of band offsets at the c-Si / a-Si interface and Schottky barrier at the a-Si / transparent conductive oxide (TCO) interface [15][18]. It was shown that the charge transport through these barriers is thermally activated [19]. Additionally, the resistivity of the a-Si layers decreases with increasing temperature [20]. These effects result in a non-linear FF behaviour with respect to the temperature. When cooling the 


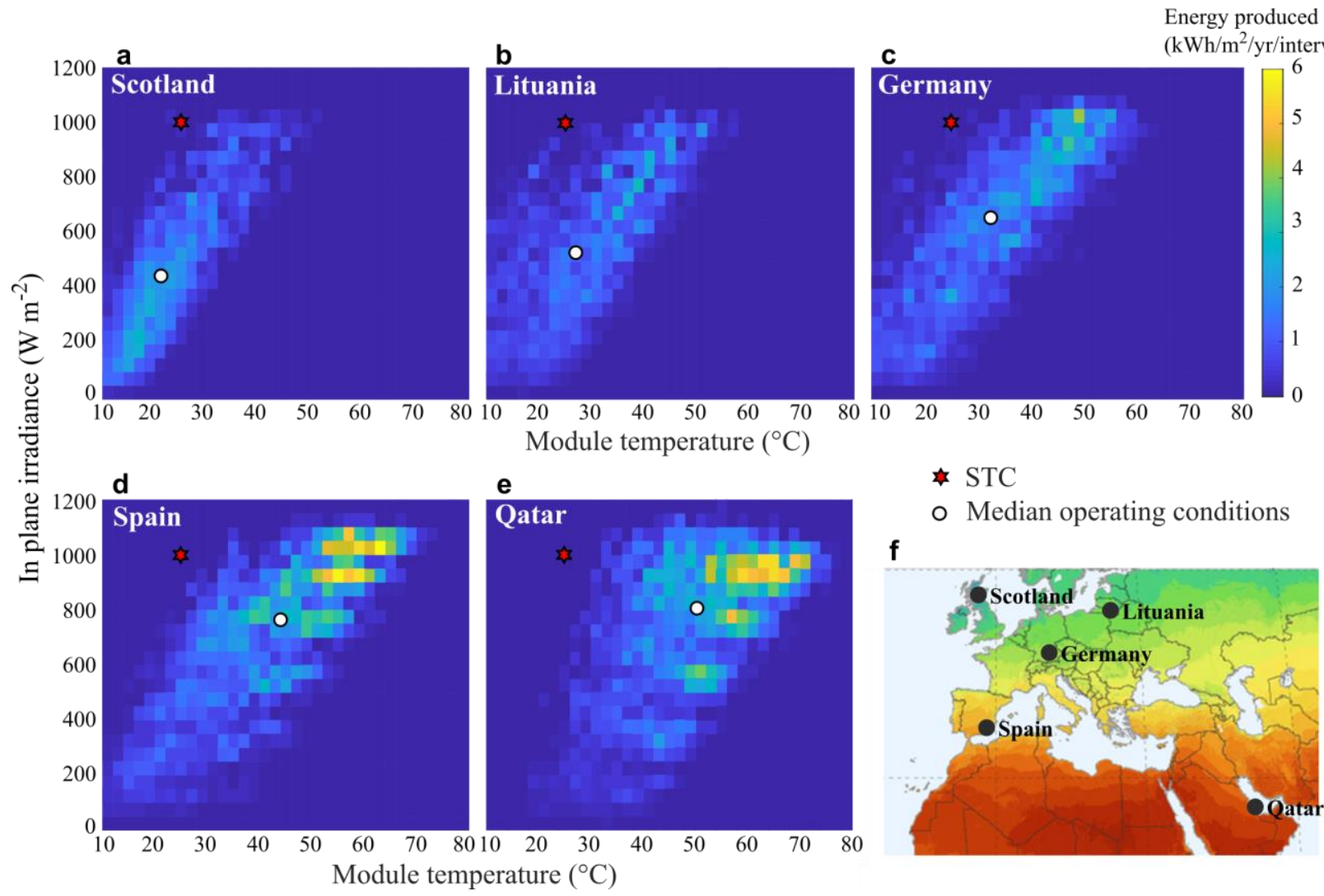

Fig. 1: a-e) Yearly produced energy as a function of the module temperature and illumination in different locations. The STC is indicated with a red star and the white dot represents the mean operating conditions weighted with the produced energy. f) Map of the locations used in this study.

solar cell, FF stops linearly increasing at a certain temperature, eventually leading to a FF maximum and a subsequent decrease at low temperature [19], [21]-[23]. Many SHJ solar cells suffer from such thermally-activated $\mathrm{R}_{\mathrm{s}}$ already at $25{ }^{\circ} \mathrm{C}$, typically leading to a modest FF below $80 \%$ which was for long a ceiling value [24]-[26]. In more severe cases, S-shaped current-voltage (IV) can be observed, which highlight that thermally activated $\mathrm{R}_{\mathrm{S}}$ components are often non-Ohmic [27]-[29]. When present, these thermally activated $\mathrm{R}_{\mathrm{S}}$ components usually decrease upon increasing temperature. This leads to an increased FF with higher temperature, which results in a further improved $\mathrm{TC}_{\eta}$ for $\mathrm{SHJ}$ compared to standard technologies as discussed in [9], [30]. Some studies aimed at solar cell architectures leading to larger current at the expense of a lower $\mathrm{FF}$ at $25^{\circ} \mathrm{C}$, with a $\mathrm{FF}$ benefitting from thermally activated $\mathrm{R}_{\mathrm{S}}$ at higher temperature [17], [30]. Seif et al. added oxygen in the front a-Si(i) layer to obtain a wider bandgap and mitigate parasitic absorption, leading to a current increase [31]. The wider bandgap of the intrinsic layer was however accompanied by a large increase of the c-Si/a-SiO valence band offset and larger resistive losses upon hole extraction. The resulting FF loss was shown to be mitigated by increasing the temperature, while the benefit of the larger current was preserved. A higher efficiency for the cell incorporating minutes amounts of oxygen in the a-Si(i) layer was thus demonstrated above 50 ${ }^{\circ} \mathrm{C}$. A similar observation was made in cells using a $\mathrm{MoO}_{\mathrm{x}}$ layer as transparent hole selective contact instead of a (p) doped layer [29]. A similar approach was followed by Haschke et al. [32], using rear-junction devices with an ndoped nanocrystalline silicon oxide (nc-SiO(n)) front layer. Similarly, the modified cells benefitted from a current increase (up to $41 \mathrm{~mA} / \mathrm{cm}^{2}$ at STC) yet a FF drop. The latter was mitigated at $60{ }^{\circ} \mathrm{C}$, yet not sufficiently to yield an efficiency improvement, and the cells with a nc-SiO(n) layer showed an overall lower efficiency also at $60{ }^{\circ} \mathrm{C}$.

In the present study, we go one step further and investigate not only the efficiency at various temperatures under 1-sun illumination, but compare yearly energy harvesting efficiencies in different climates, thus accounting for both temperature and illumination intensity. To highlight the efficiency shift as a function of temperature and illumination, we use cells with various concentrations of carbon in the front (n)-doped layer. Adding carbon results in a bandgap widening, yielding a higher transparency but hampers charge extraction. Although this is shown to result in an overall performance decrease at STC, the higher operating temperature and/or lower irradiance during operation makes the solar cell incorporating carbon outperform the carbonfree solar cell in terms of yearly harvesting efficiency in all considered climates.

\section{EXPERIMENTAL DETAILS}

The solar cells presented in this study were all fabricated using float-zone, $180-\mu \mathrm{m}$-thick, n-type $(2 \Omega \mathrm{cm})$ silicon wafers, textured by alkaline etching. Before the a-Si layers deposition, an HF solution was used to remove native oxide
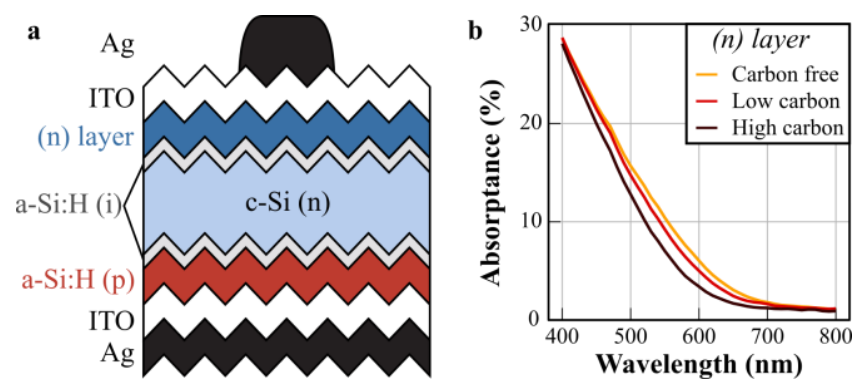

Fig. 2: a) Scheme of a typical rear-junction SHJ cell. b) Absorptance of the three investigated $(n)$ doped lavers in the visible range. 


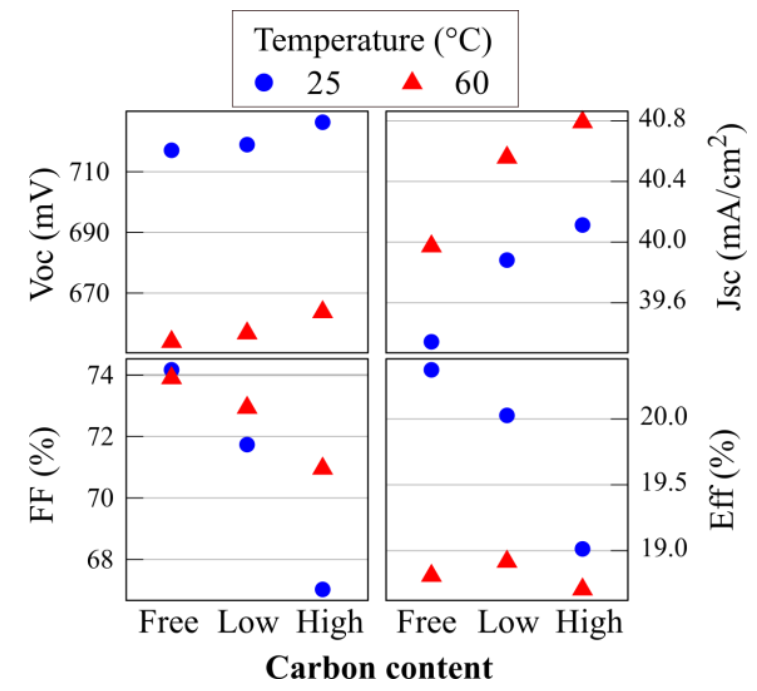

Fig. 3: IV characteristics of cells with various carbon content in the front (n) layer at $25^{\circ} \mathrm{C}$ and $60^{\circ} \mathrm{C}$ under 1 -sun illumination.

from the surfaces. The a-Si layers were deposited in a plasma-enhanced chemical vapour deposition (PECVD) reactor. For the carbide n-type layers, $\mathrm{CH}_{4}$ was added to the gas mixture composed of $\mathrm{SiH}_{4}, \mathrm{H}_{2}$ and $\mathrm{PH}_{3}$. Methane to silane ratio of $0,0.4$ and 1 were used for the samples presented below, referred respectively as carbon-free (reference), low-carbon and high-carbon.

ITO layers and rear silver metallisation were deposited by magnetron sputtering. The front metallisation was made of screen printed silver paste cured at $210{ }^{\circ} \mathrm{C}$ for 30 minutes. Five $2 \times 2 \mathrm{~cm}^{2}$ cells were made on each wafer. Additional details on the fabrication process can be found in ref. [31].

After the cell metallization, current-voltage IV characteristics were measured at STC $\left(25{ }^{\circ} \mathrm{C}, 1000 \mathrm{~W} / \mathrm{m}^{2}\right.$ AM1.5G spectrum) using a class AAA standard solar simulator. Additional IV measurements from $15^{\circ} \mathrm{C}$ to $80{ }^{\circ} \mathrm{C}$ with $5{ }^{\circ} \mathrm{C}$ steps were performed using LED and halogen based solar simulator equipped with a thermoelectric holder and a PT100 temperature probe. For each of the 14 temperature steps, an IV curve was measured at 8 different light intensities, calibrated with a reference cell (the measurement conditions are shown in Fig. 4). The measurement uncertainty was probed by 25 successive measurements using a reference sample following the full measurement process each time (including removing and placing back the sample on the measurement setup), in the same conditions as the actual measurements presented in this study. For measurements performed on the same day (as was the case in this study), the incertitude of temperature and lights intensity are measured to be well below $1{ }^{\circ} \mathrm{C}$ and $10 \mathrm{~W} / \mathrm{m}^{2}$, respectively. The standard deviation of the IV parameters are the following: efficiency $-0.033 \%$ absolute, $\mathrm{V}_{\text {oc }}-0.075 \mathrm{mV}$, FF $0.078 \%_{\text {absolute }}, \mathrm{J}_{\mathrm{sc}}-0.047 \mathrm{~mA} / \mathrm{cm}^{2}$.

The extensive measurement ranges enable to plot maps of the device efficiency as a function of temperature and irradiance (see Fig. 4). These maps were then used together with weather data to simulate the harvesting efficiency expected in various locations. The heat source $(Q)$ in the device was calculated as the fraction of the spectrally resolved incident absorbed irradiance (calculated using SunSolve ${ }^{\mathrm{TM}}$ from PVlighthouse [33]) minus the electrically produced power. Note that an iterative calculation was employed since PV conversion efficiency varies with temperature via the socalled temperature coefficient. The device temperature was calculated using the ambient temperature $\left(T_{a m b}\right)$, heat transfer coefficients $\left(u_{0}, u_{1}\right)$ based on outdoor measurements taken from ref. [34], and as a function of the wind velocity $\left(v_{w}\right)$ [2]:

$$
T_{\text {module }}=T_{a m b}+\frac{Q}{u}
$$

With $u=u_{0}+u_{1} v_{w}$, the global heat transfer coefficient that accounts for all the heat transfer mechanisms. The produced power was calculated in 1-hour-intervals over a complete year. The median of the operating conditions, weighted by the produced energy, is defined as the condition for which half of the harvested energy is produced at higher temperature, half at lower temperature, half at higher illumination and half at lower illumination (shown as white dots in Fig. 1a-e). More details on the modelling framework can be found in [35]. Energy harvesting simulations were carried out in the locations shown in Fig. 1, representing different climatic conditions.

\section{RESULTS \& DISCUSSION}

A) Solar cell efficiency in various conditions Fig. 3 shows IV characteristics of the cells with different carbon content in the front doped layer, at STC and for the same illumination, but at a temperature of $60{ }^{\circ} \mathrm{C}$. At STC, the cells with high carbon content show a slightly larger $\mathrm{V}_{\mathrm{oc}}$ than the other two (i.e. carbon-free and low-carbon ones), yet this difference is quite small and could be linked to the fluctuation in the passivation quality. Then, the sample incorporating low (respectively high) carbon concentration shows a 0.5 $\mathrm{mA} / \mathrm{cm}^{2}$ (respectively $0.8 \mathrm{~mA} / \mathrm{cm}^{2}$ ) current gain compared to the reference cell, thanks to the more transparent a-SiC(n) layer. This higher transparency can also be measured by spectrometry of layers co-deposited on glass (Fig. 2) and originates from a wider bandgap [36]-[38]. However the incorporation of carbon leads to a FF reduction through an

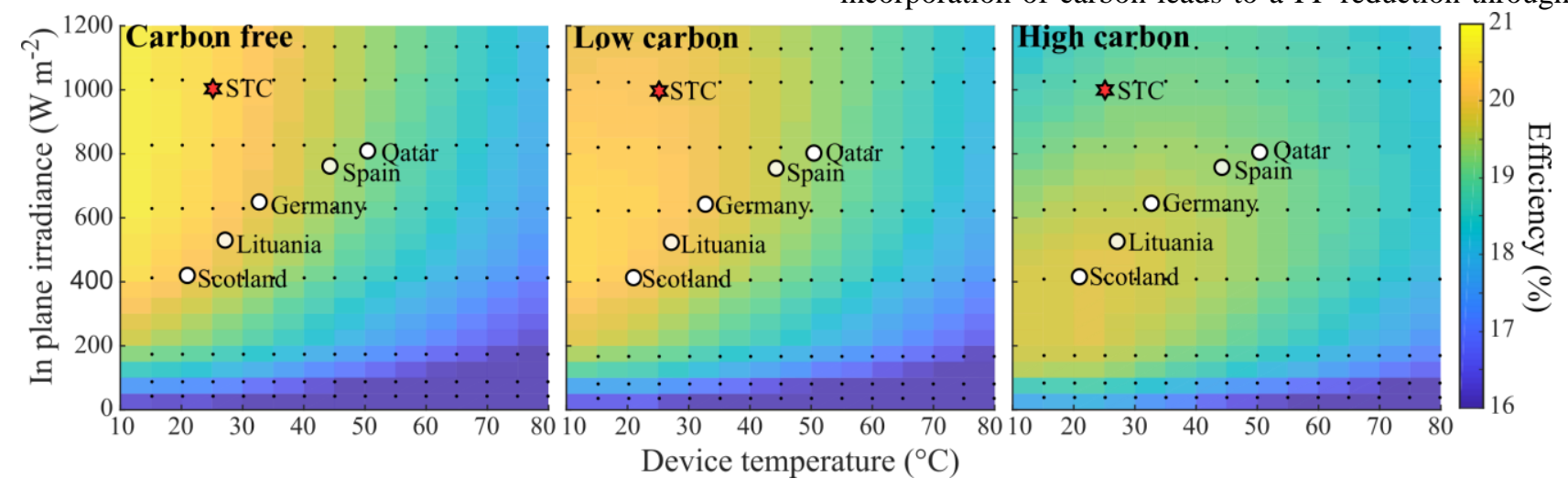

Fig. 4: Measured efficiency map as a function of the temperature and illumination for cells with different carbon concentration in the front (n) layer. Each black dot represents one of the 9x14 measurement conditions for each sample. 

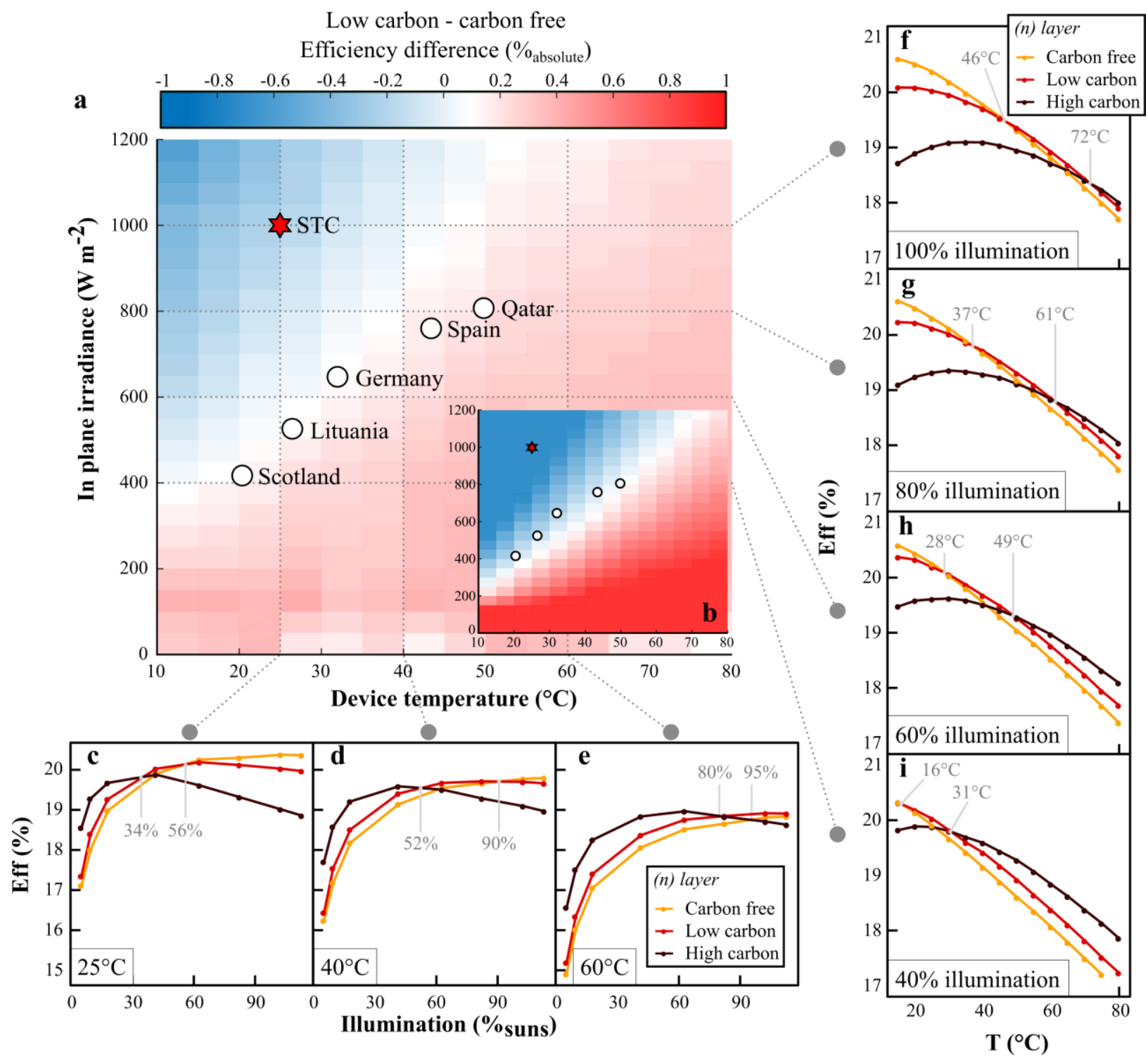

Fig. 5: a,b) Efficiency difference between the carbon-free cell and the cell with low carbon content (n) layer (the inset in b shows the difference with the high carbon content) as a function of the operating conditions. In the red zones, the low-carbon cell is more efficient than the carbon free cell. The STC condition is highlighted with a red star and the white dots are the energy-weighted median operating conditions of the different studied locations. c-e) Efficiency as a function of the illumination for different temperatures. f-i) Efficiency as a function of the temperature for different illumination.

increase of the $R_{s}$. This could possibly be caused by a larger conduction band offset or by a larger layer bulk resistivity [39]-[42]. At $25{ }^{\circ} \mathrm{C}$, this higher resistance leads to a $2.5 \%$ absolute (respectively $7.1 \%$ absolute FF loss compared to the reference sample. These competing effects lead to an efficiency $0.3 \%$ absolute (respectively $1.4 \%_{\text {absolute }}$ ) lower.

When measuring the solar cell at $60{ }^{\circ} \mathrm{C}, \mathrm{V}_{\mathrm{oc}}$ is lower and $\mathrm{J}_{\mathrm{sc}}$ has increased similarly for all samples, as would be expected from classical solar cell theory [43], thus not changing the trends between samples. Yet, the FF of all devices does not follow the $\mathrm{V}_{\mathrm{oc}}$-driven decrease as known from homojunction solar cells; either it does not change (for the carbon-free cell) or it even increases (for cells incorporating carbon). This stems from the presence of thermally activated resistances to charge extraction in these devices, as discussed in the introduction. As a result, the loss of FF associated to carbon incorporation is much lower at $60{ }^{\circ} \mathrm{C}$ than $25^{\circ} \mathrm{C}$. The $\mathrm{FF}$ of the low carbon (respectively high carbon) device is only $0.9 \%$ absolute (respectively $2.9 \%$ absolute) lower than the reference cell. This leads to an efficiency gain of $0.1 \%$ absolute (respectively a loss of $-0.1 \%_{\text {absolute }}$ ) at $60{ }^{\circ} \mathrm{C}$ compared to the reference for the low-carbon (resp. high-carbon) samples. We focus in the following on the efficiency only and investigate mainly the effect of irradiances and temperatures of operation.

Fig. 4 shows the efficiency maps for the three devices measured at various operating temperatures and illumination intensities. The operating condition yielding the highest efficiency is shifting towards lower illumination and higher temperature upon carbon incorporation, as expected from the presence of aforementioned thermally activated transport barriers: Increasing temperature reduces the absolute value of $R_{s}$, whereas decreasing illumination decreases the impact of $\mathrm{R}_{\mathrm{s}}$ due to the increase of the impedance at the maximum power point [9]. Furthermore, since the current gain originating from the more transparent front layer stands at any temperature and illumination, the efficiency of the cells with carbon in the front (n) layer exceeds the one of the reference cell at high-enough temperature or low-enough illumination.

Fig. 5 further illustrates the difference between the various architectures: Fig. 5a shows an irradiance-temperature map of the subtraction between the efficiency of the carbon-free and the low-carbon samples, whereas Fig. 5c-e (resp. Figs. 
5f-i) show efficiency values of the three samples at given temperatures (resp. illuminations intensities). These views are indicative of the range for which a given carbon concentration in the (n) layer yields a better efficiency than the other one. For example, Fig. $5 \mathrm{f}$ shows that at $1000 \mathrm{~W} / \mathrm{m}^{2}$ (corresponding to 1 sun), the low-carbon cell efficiency exceeds the reference-cell efficiency for temperatures over $50{ }^{\circ} \mathrm{C}$, whereas at $400 \mathrm{~W} / \mathrm{m}^{2}$ (Fig. $5 \mathrm{~h}$ ), the crossover occurs at $20{ }^{\circ} \mathrm{C}$ already. This lowering of the crossover temperature highlights that, especially in the case of heterojunction devices, the operating condition can change the hierarchy of efficiency between devices employing different contact layers.

Back to Fig. 5a, the upper-left corner of the measurement window (low temperature and high illumination) corresponds to conditions for which the carbon-free cell is more efficient as the low-carbon cell suffers from its higher $\mathrm{R}_{\mathrm{s}}$. However, this difference is reduced both by a lower illumination or a higher temperature, reaching a limit where the cells are equivalent (white areas in Fig. 5a). At these points, the resistive losses in the sample with carbon are compensated by the larger current. Reducing further the illumination intensity or increasing further the temperature, the lowcarbon sample shows increasingly better efficiency than the reference cell. When comparing the carbon-free to the highcarbon cell (as shown in Fig. 5b), this trend is further amplified, shifting the equivalent-efficiency-line towards lower illumination and higher temperature. Thus, the efficiency gain at low illumination and high temperature is even larger than that recorded for the low carbon cell. Note that there is not always a crossover point (or at least not for field-relevant conditions), since the addition of oxygen in the film in lieu of carbon yielded a systematic decrease of performance for all field-relevant temperature-illumination couples.

\section{B) Harvesting efficiency calculations}

In view of the different behaviour of the efficiency with respect to the temperature and illumination for the various cell architectures, we calculated the total yearly average
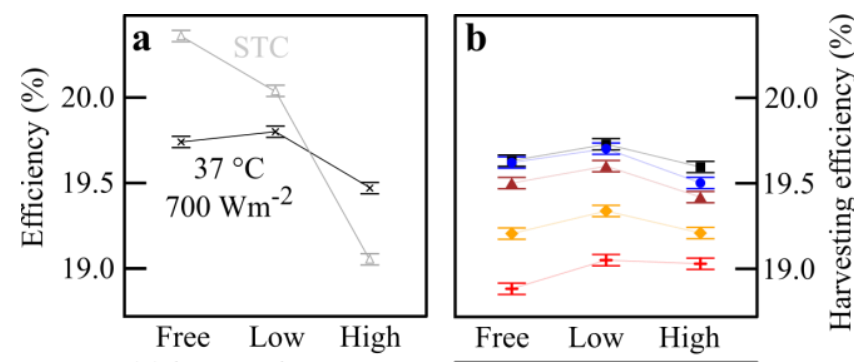

(n) layer carbon content

- Scotland

- Lituania

- Germany

- Spain

+ Qatar

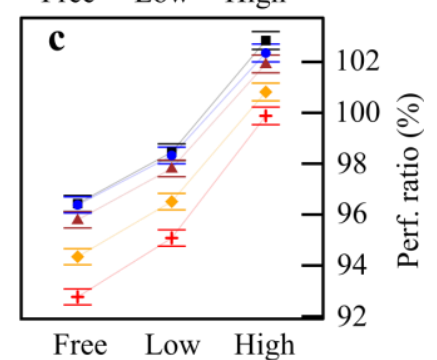

(n) layer carbon content

Fig. 6: a) Efficiency at STC and at "realistic test conditions" $\left(37{ }^{\circ} \mathrm{C}\right.$, $700 \mathrm{Wm}^{-2}$ ). b) Harvesting efficiency as a function of the (n) layer carbon concentration in the different investigated climates. c) Performance ratio as a function of the (n) layer carbon concentration in the different investigated climates. The error bars show the measurement uncertainty.

efficiency, or harvesting efficiency (cf. (Eq. 1)) output of the three investigated samples, in the climates mentioned above to allow a relevant comparison of their respective potential for electricity generation. These results are shown in Fig. 6: the sample with a low-carbon content, despite its lower efficiency at STC, produces more energy in all the considered climates. This harvesting efficiency difference is larger in the hot climates, reaching $+0.8 \%$ relative in Qatar. Interestingly, the low-carbon cell in moderate climates also shows a gain of about $+0.5 \%$ relative, this time originating from the low illumination compared to STC. The sample with the highcarbon (n) layer is less efficient than the carbon-free sample in the moderate climates due to the resistive losses at low temperature. However, in very hot climates such as Qatar, a gain is observed compared to the reference similarly to the low-carbon samples. Thus, within the investigated conditions, the larger the carbon content is, the lower the STC efficiency is, but also the larger performance ratio is (Fig. 6c) [44]. This overall results in similar harvesting efficiencies in outdoor conditions, confirming that STC efficiency values can be misleading if the performance ratio is not considered. Finally, it is worth noting that the yearly-integrated harvesting efficiency differs from the cell efficiency at the weighted median operating conditions. Using the median conditions for cell optimisation is thus more realistic than considering solely STC conditions, however the integration over the whole data is still needed for an accurate estimation of the harvesting efficiency. For a rapid estimation of an outdoor cell performance without computing the climatic data integration, an illumination of $700 \mathrm{~W} / \mathrm{m}^{2}$ and a temperature of $37{ }^{\circ} \mathrm{C}$ (corresponding to the global mean operating conditions of all considered climates) can be used, as shown in Fig. 6.

\section{CONCLUSION}

We compared the performance of silicon heterojunction solar cells using different carbon concentrations in the front (n) layer, leading to higher transparency but also higher resistive losses. We discuss the efficiency at different operating conditions, and harvesting efficiency in various climates. We evidence that the mean operating conditions of a solar module in real outdoor situations do not match STC and are shifted to lower illumination for all the investigated climates, and to usually higher temperature, particularly in hot climates. At STC, the resistive losses outweigh the optical gains, making the carbon-free cell the most efficient one. Upon increasing temperature or decreasing illumination, the optimum shifts towards the incorporation of carbon in the (n) layer. As a result, the device with a little carbon incorporation outperforms the reference device in all considered climates thanks to its larger harvesting efficiency. In moderate climates such as Scotland, a $0.5 \%$ relative efficiency gain is observed which reached $0.8 \%$ relative in arid climates such as Qatar. These trends could not have been deduced from STC measurements, yet a measurement at a more realistic average operating condition at $37{ }^{\circ} \mathrm{C}$ and $700 \mathrm{~W} / \mathrm{m}^{2}$ (corresponding to the global mean operating conditions of all considered climates) would have hinted towards them. This highlights the need to calculate harvesting efficiencies in various climates when comparing solar cell designs.

\section{ACKNOWLEDGMENTS}

The authors acknowledge Nicolas Badel, Patrick Wyss and Christophe Allebé for the high quality wet-processing and 
metallisation. We also thank Cédric Bucher and Aymeric Schafflützel for technical support.

This work was funded by Qatar Foundation and by the European Union's Horizon 2020 research and innovation programs under Grant Agreement No. 745601 (Ampere).

\section{REFERENCES}

[1] M. Schweiger, J. Bonilla, W. Herrmann, A. Gerber, and U. Rau, "Performance stability of photovoltaic modules in different climates," Prog. Photovoltaics Res. Appl., vol. 25, no. 12, pp. 968-981, Dec. 2017.

[2] O. Dupré, R. Vaillon, and M. A. Green, Thermal Behavior of Photovoltaic Devices. Cham: Springer International Publishing, 2017.

[3] A. Abdallah, D. Martinez, B. Figgis, and O. El Daif, "Performance of Silicon Heterojunction Photovoltaic modules in Qatar climatic conditions," Renew. Energy, vol. 97, pp. 860-865, 2016.

[4] A. Louwen, A. C. de Waal, R. E. I. Schropp, A. P. C. Faaij, and W. G. J. H. M. van Sark, "Comprehensive characterisation and analysis of PV module performance under real operating conditions," Prog. Photovoltaics Res. Appl., vol. 25, no. 3, pp. 218-232, Mar. 2017.

[5] C. Cañete, J. Carretero, and M. Sidrach-de-Cardona, "Energy performance of different photovoltaic module technologies under outdoor conditions," Energy, vol. 65, pp. 295-302, 2014.

[6] T. Huld, A. M. Gracia Amillo, T. Sample, E. D. Dunlop, E. Salis, and R. P. Kenny, "The completed IEC 61853 Standard on PV Module Energy Rating, Overview, Applications and Outlook," 2018.

[7] L. M. Ayompe, A. Duffy, S. J. McCormack, and M. Conlon, "Measured performance of a $1.72 \mathrm{~kW}$ rooftop grid connected photovoltaic system in Ireland," Energy Convers. Manag., vol. 52, no. 2, pp. 816-825, Feb. 2011.

[8] M. A. Green, "General temperature dependence of solar cell performance and implications for device modelling," Prog. Photovoltaics Res. Appl., vol. 11, no. 5, pp. 333-340, 2003.

[9] J. Haschke et al., "The impact of silicon solar cell architecture and cell interconnection on energy yield in hot \& sunny climates," Energy Environ. Sci., vol. 10, no. 5, pp. 1196-1206, 2017.

[10] M. A. Green, K. Emery, and A. W. Blakers, "Silicon solar cells with reduced temperature sensitivity," Electron. Lett., vol. 18, no. 2, pp. 97-98, 1982.

[11] N. Aste, C. Del Pero, and F. Leonforte, "PV technologies performance comparison in temperate climates," Sol. Energy, vol. 109, pp. 1-10, 2014.

[12] V. Sharma, A. Kumar, O. S. Sastry, and S. S. Chandel, "Performance assessment of different solar photovoltaic technologies under similar outdoor conditions," Energy, vol. 58, pp. 511-518, 2013.

[13] T. Mishima, M. Taguchi, H. Sakata, and E. Maruyama, "Development status of high-efficiency HIT solar cells," Sol. Energy Mater. Sol. Cells, vol. 95, no. 1, pp. 18-21, Jan. 2011.

[14] M. Taguchi, A. Terakawa, E. Maruyama, and M. Tanaka, "Obtaining a higher Voc in HIT cells," Prog. Photovoltaics Res. Appl., vol. 13, no. 6, pp. 481-488, 2005.

[15] R. Varache, J. P. Kleider, W. Favre, and L. Korte, "Band bending and determination of band offsets in amorphous/crystalline silicon heterostructures from planar conductance measurements," J. Appl. Phys., vol. 112, no. 12, 2012.

[16] M. Bivour, S. Schröer, and M. Hermle, "Numerical Analysis of Electrical TCO / a-Si:H(p) Contact Properties for Silicon Heterojunction Solar Cells," Energy Procedia, vol. 38, pp. 658-669, Jan. 2013.

[17] M. Mews, M. Liebhaber, B. Rech, and L. Korte, "Valence band alignment and hole transport in amorphous/crystalline silicon heterojunction solar cells," Appl. Phys. Lett., vol. 107, no. 1, p. 013902 , 2015.

[18] S. Kirner et al., "The Influence of ITO Dopant Density on J-V Characteristics of Silicon Heterojunction Solar Cells: Experiments and Simulations," Energy Procedia, vol. 77, no. i, pp. 725-732, 2015.

[19] M. Taguchi, E. Maruyama, and M. Tanaka, "Temperature Dependence of Amorphous/Crystalline Silicon Heterojunction Solar Cells," Jpn. J. Appl. Phys., vol. 47, no. 2, pp. 814818, 2008

[20] A. V. Shah, Thin-Film Silicon Solar Cells. EPFL Press, 2010.

[21] J. P. Seif et al., "Asymmetric band offsets in silicon heterojunction solar cells: Impact on device performance," J. Appl. Phys., vol. 120, no. 5, 2016.

[22] A. V. Sachenko et al., "Temperature dependence of photoconversion efficiency in silicon heterojunction solar cells: Theory vs experiment," J. Appl. Phys., vol. 119, no. 22, p. 225702, Jun. 2016.

[23] A. V. Sachenko et al., "The temperature dependence of the characteristics of crystalline-silicon-based heterojunction solar cells," Tech. Phys. Lett., vol. 42, no. 3, pp. 313-316, 2016.

[24] D. Adachi, J. L. Hernández, and K. Yamamoto, "Impact of carrier recombination on fill factor for large area heterojunction crystalline silicon solar cell with 25.1\% efficiency," Appl. Phys. Lett., vol. 107, no. 23, p. 233506, Dec. 2015.

[25] S. De Wolf, A. Descoeudres, Z. C. Holman, and C. Ballif, "High-efficiency Silicon Heterojunction Solar Cells: A Review," Green, vol. 2, no. 1, pp. 7-24, 2012.

[26] J. Haschke, O. Dupré, M. Boccard, and C. Ballif, "Silicon heterojunction solar cells: Recent technological development and practical aspects from lab to industry," Sol. Energy Mater. Sol. Cells, vol. 187, pp. 140-153, Dec. 2018.

[27] L. Sims et al., "Investigation of the s-shape caused by the hole selective layer in bulk heterojunction solar cells," Org. Electron., vol. 15, no. 11, pp. 2862 2867, Nov. 2014.

[28] R. V. K. Chavali, J. R. Wilcox, B. Ray, J. L. Gray, and M. A. Alam, "Correlated Nonideal Effects of Dark and Light I-V Characteristics in a-Si/c-Si Heterojunction Solar Cells," IEEE J. Photovoltaics, vol. 4, no. 3, pp. 763-771, 2014.

[29] C. Battaglia et al., "Silicon heterojunction solar cell with passivated hole selective MoOx contact," Appl. Phys. Lett., vol. 104, no. 11, p. 113902, Mar. 2014.

[30] L. Mazzarella, S. Kirner, B. Stannowski, L. Korte, B Rech, and R. Schlatmann, "p-type microcrystalline silicon oxide emitter for silicon heterojunction solar cells allowing current densities above $40 \mathrm{~mA} / \mathrm{cm} 2$," 
Appl. Phys. Lett., vol. 106, p. 023902, 2015.

[31] J. P. Seif et al., "Amorphous silicon oxide window layers for high-efficiency silicon heterojunction solar cells," J. Appl. Phys., vol. 115, no. 2, p. 24502, 2014.

[32] J. Haschke et al., "Nanocrystalline silicon oxide stacks for silicon heterojunction solar cells for hot climates," in AIP Conference Proceedings, 2018, vol. 1999, no. 1, p. 030001.

[33] "PVlighthouse SunSolve TM.".

[34] M. Koehl, M. Heck, S. Wiesmeier, and J. Wirth, "Modeling of the nominal operating cell temperature based on outdoor weathering," Sol. Energy Mater. Sol. Cells, vol. 95, no. 7, pp. 1638-1646, Jul. 2011.

[35] O. Dupré, A. Tuomiranta, Q. Jeangros, M. Boccard, P.-J. Alet, and C. Ballif, "Design rules to fully benefit from bifaciality in two-terminal tandem solar cells," Rev., 2019.

[36] M. Zeman, G. Papakonstantinou, R. A. C. M. M. van Swaaij, D. Deligiannis, and D. Zhang, "Optical Enhancement of Silicon Heterojunction Solar Cells With Hydrogenated Amorphous Silicon Carbide Emitter," IEEE J. Photovoltaics, vol. 4, no. 6, pp. 1326-1330, 2014.

[37] D.-W. Kang, P. Sichanugrist, H. Zhang, and M. Konagai, "Wide-bandgap p-type microcrystalline silicon oxycarbide using additional trimethylboron for silicon heterojunction solar cells," Prog. Photovoltaics Res. Appl., vol. 15, no. February 2013, pp. 659-676, 2017.

[38] Z. Qiao, J.-L. Ji, Y.-L. Zhang, H. Liu, and T.-K. Li, "Influence of interface states, conduction band offset, and front contact on the performance of a$\mathrm{SiC}: \mathrm{H}(\mathrm{n}) / \mathrm{c}-\mathrm{Si}(\mathrm{p})$ heterojunction solar cells," Chinese Phys. B, vol. 26, no. 6, p. 068802, Jun. 2017.

[39] Y. Tawada, M. Kondo, H. Okamoto, and Y. Hamakawa, "Hydrogenated amorphous silicon carbide as a window material for high efficiency a-Si solar cells," Sol. Energy Mater., vol. 6, no. 3, pp. 299-315, 1982.

[40] M. Boccard and Z. C. Holman, "Amorphous silicon carbide passivating layers for crystalline-siliconbased heterojunction solar cells," J. Appl. Phys., vol. 118 , no. 6, 2015.

[41] T. F. Schulze, L. Korte, F. Ruske, and B. Rech, "Band lineup in amorphous/crystalline silicon heterojunctions and the impact of hydrogen microstructure and topological disorder," Phys. Rev. B - Condens. Matter Mater. Phys., vol. 83, no. 16, pp. 1-11, 2011.

[42] A. Kanevce and W. K. Metzger, "The role of amorphous silicon and tunneling in heterojunction with intrinsic thin layer (HIT) solar cells," J. Appl. Phys., vol. 105, no. 9, p. 094507, May 2009.

[43] O. Dupré, R. Vaillon, and M. A. Green, "Physics of the temperature coefficients of solar cells," Sol. Energy Mater. Sol. Cells, vol. 140, pp. 92-100, 2015.

[44] D. Rose, O. Koehler, B. Bourne, D. Kavulak, and L. Nelson, "High-Confidence Prediction of Energy Production From High-Efficiency Photovoltaic Systems," 2010. 
This is the accepted version of the article "Optimized Design of Silicon Heterojunction Solar Cells for Field Operating Conditions” from J. Cattin et al., DOI: 10.1109/JPHOTOV.2019.2938449

(C) 2019 IEEE. Personal use of this material is permitted. Permission from IEEE must be obtained for all other uses, in any current or future media, including reprinting/republishing this material for advertising or promotional purposes, creating new collective works, for resale or redistribution to servers or lists, or reuse of any copyrighted component of this work in other works.

Publisher version available at

https://doi.org/10.1109/JPHOTOV.2019.2938449 